\title{
Ethyl Pyruvate Downregulates Tumor Necrosis Factor Alpha and Interleukin (IL)-6 and Upregulates IL-10 in Lipopolysaccharide-Stimulated Canine Peripheral Blood Mononuclear Cells
}

\author{
Do-Hyeon $\mathrm{YU}^{1)}$, Dong-Ho $\mathrm{NOH}^{1)}$, Ru-Hui SONG ${ }^{1)}$ and Jinho PARK ${ }^{1) *}$ \\ ${ }^{1)}$ College of Veterinary Medicine \& Bio-Safety Research Institute, Chonbuk National University, Jeonju, Jeonbuk 561-756, South Korea
}

(Received 29 December 2009/Accepted 7 May 2010/Published online in J-STAGE 21 May 2010)

ABSTRACT. We investigated the anti-inflammatory effects of ethyl pyruvate (EP) on LPS-stimulated canine PBMCs in vitro. We found that EP treatment inhibited the mRNA expressions of proinflammatory cytokines (TNF- $\alpha$ and IL-6), but induced mRNA expression of anti-inflammatory cytokines (IL-10). ELISA measurements revealed that EP also effectively downregulates the LPS-induced increase in proinflammatory cytokine release, while upregulating anti-inflammatory cytokine release. These data indicate that EP could be an effective anti-inflammatory agent in dogs.

KEY WORDS: canine peripheral blood mononuclear cells, cytokine, ethyl pyruvate, mRNA.

Ethyl pyruvate (EP) is a simple aliphatic ester derived from the endogenous metabolite pyruvic acid and has been shown to exhibit antioxidant [5] and anti-inflammatory [1] properties. While EP is known to inhibit activation of p28 mitogen-activated protein kinase and NF- $\kappa \mathrm{B}$ in murine macrophages [10], its anti-inflammatory mechanism remains unclear.

We hypothesized that lipopolysaccharide (LPS) treatment of canine PBMCs would induce proinflammatory cytokine expression and that EP would attenuate this increase at either the mRNA or protein level. To address this hypothesis, we selected TNF- $\alpha$ and IL- 6 as representative proinflammatory cytokines that are upregulated after LPS administration. In addition, we selected IL-10 as an anti-inflammatory cytokine.

Blood was collected from six healthy beagles and peripheral blood mononuclear cells (PBMCs) were separated using Histopaque ${ }^{\circledR} 1077$ (Sigma, St. Louis, MO, U.S.A.). The isolated PBMCs were seeded into 24-well Nunclon ${ }^{\circledR}$ plates (NUNC, Roskilde, Denmark) in a final volume of $2 \times$ $10^{6}$ cells $/ \mathrm{m} l$, supplemented with RPMI-1640 (Hyclone ${ }^{\circledR}$, Thermo Fisher Scientific Inc., Logan, UT, U.S.A.) medium, $10 \%$ heat-inactivated FBS (fetal bovine serum, Hyclone ${ }^{\circledR}$, Thermo Fisher Scientific Inc.) and $100 \mathrm{U} / \mathrm{ml}$ penicillin $\mathrm{G}$ and $10 \mu \mathrm{g} / \mathrm{m} l$ streptomycin (Sigma) at $37^{\circ} \mathrm{C}$ in $5 \% \mathrm{CO}_{2}$ and incubated overnight. The next day, the mononuclear cells were exposed to $100 \mathrm{ng} / \mathrm{m} l$ of LPS (Escherichia coli serotype O111: B4, Sigma) and simultaneously treated with various concentrations of EP (Sigma) ( $5 \mathrm{~d} 10 \mathrm{mM}$ each) based on previous in vitro studies [9]. The cell pellets were used for RNA isolation, and the cell-free supernatants were stored at $-80^{\circ} \mathrm{C}$ until they were analyzed. Samples were harvested after 3, 6, 12 and $24 \mathrm{hr}$ of cultivation. Unstimu-

\footnotetext{
* Correspondence to: Park, J., College of Veterinary Medicine, Chonbuk National University, Jeonju, Jeonbuk 561-756, South Korea.

e-mail: jpark@jbnu.ac.kr
}

lated cells and cells in $10 \mathrm{mM}$ ethyl pyruvate were used as controls. All procedures used in this study were approved by local animal welfare authorities (CBU2008-021).

For the quantification of cytokine gene expression, $\mathrm{SYBR}^{\circledR}$ green real-time PCR was used. Total RNA was extracted using an RNeasy ${ }^{\circledR}$ Mini Kit (Qiagen $\mathrm{GmbH}$, Hilden, Germany), and subsequent DNase digestion was performed using RNase-free DNase (RQ1 RNase-free DNase, Promega, Madison, WI, U.S.A.). Five hundred nanograms to one microgram of total RNA was reverse transcribed in a $20 \mu l$ reaction volume containing random hexamers, dNTP mixture, reverse transcriptase, recombinant RNase inhibitor, DTT and $5 \times$ First-Strand Buffer. Then, $1 \mu l$ of $E$. coli RNase $H$ was added and incubated at $37^{\circ} \mathrm{C}$ for $20 \mathrm{~min}$. All materials were purchased from Invitrogen Corporation (SuperScript ${ }^{\mathrm{TM}}$ III, Invitrogen, Carlsbad, CA, U.S.A.). PCR was performed in a $20 \mu l$ reaction volume containing $300 \mathrm{nM}$ of each primer, $1 \mu l$ of cDNA and $10 \mu l$ of $2 \times \mathrm{iQ}^{\mathrm{TM}} \mathrm{SYBR}^{\circledR}$ Green Supermix (Bio-Rad, Hercules, CA, U.S.A.) using the CFX384 Real-Time PCR detection system (Bio-Rad) and the following steps: an initial i-Taq ${ }^{\mathrm{TM}}$ DNA polymerase activation step at $95^{\circ} \mathrm{C}$ for 3 min, 40 cycles of denaturation for $15 \mathrm{sec}$ at $95^{\circ} \mathrm{C}$ and $15 \mathrm{sec}$ at the annealing temperature and then $15 \mathrm{sec}$ at $72^{\circ} \mathrm{C}$ for extension. Data collection and analysis were performed using the CFX Manager ${ }^{\mathrm{TM}}$ Software version 1.0 (Bio-Rad). The primers utilized in this study are summarized in Table 1. The optimal annealing temperature $\left(\mathrm{T}_{\mathrm{a}}\right)$ for all assays ranged from $60^{\circ} \mathrm{C}$ for GAPDH and IL- 6 to $62^{\circ} \mathrm{C}$ for TNF- $\alpha$ and IL-10. Primer efficiency calculations $\left[E(\%)=\left(10^{(1 /-\mathrm{S})}\right.\right.$ 1) $\times 100, S=$ slope] for all of the standard lines were between 95.7 and $102.4 \%$. Relative quantification was analyzed using the $-2^{\triangle \triangle C T}$ method as previously described [4]. Tests were performed in duplicate.

Our quantification of cytokine mRNA abundance demonstrated that EP inhibits TNF- $\alpha$ and IL- 6 mRNA synthesis and promotes IL-10 mRNA expression on LPS stimulation, 
Table 1. $\quad$ Primers used for the $\mathrm{SYBR}^{\circledR}$ green real-time PCR assay

\begin{tabular}{|c|c|c|c|c|c|c|c|c|c|c|}
\hline \multirow{2}{*}{$\begin{array}{l}\text { Target } \\
\text { gene }\end{array}$} & \multirow{2}{*}{$\begin{array}{c}\text { GenBank } \\
\text { accession No. }\end{array}$} & \multicolumn{3}{|c|}{ Forward primer } & \multirow[b]{2}{*}{ Forward sequences } & \multicolumn{3}{|c|}{ Reverse primer } & \multirow[b]{2}{*}{ Reverse sequences } & \multirow{2}{*}{$\begin{array}{l}\text { Amplicon } \\
\text { size (bp) }\end{array}$} \\
\hline & & Start ${ }^{\mathrm{a})}$ & $\begin{array}{l}\left.\mathrm{T}_{\mathrm{m}}^{\mathrm{b}}\right) \\
\left({ }^{\circ} \mathrm{C}\right)\end{array}$ & $\begin{array}{l}\text { GC } \\
(\%)\end{array}$ & & Start ${ }^{\mathrm{a})}$ & $\begin{array}{l}\mathrm{T}_{\mathrm{m}}^{\mathrm{b})} \\
\left({ }^{\circ} \mathrm{C}\right)\end{array}$ & $\begin{array}{l}\mathrm{GC} \\
(\%)\end{array}$ & & \\
\hline GAPDH & AB038240 & 698 & 59 & 58 & TCСССАСССССAATGTATC & 789 & 58 & 50 & TGCCTGCTTCACTACCTTCTTG & 92 \\
\hline TNF- $\alpha$ & $\begin{array}{l}\text { NM } \\
001003224\end{array}$ & 726 & 59 & 50 & CCAAACCGACCCTTTGATCA & 808 & 59 & 55 & CCAGCCCTGAGCCCTTAATT & 83 \\
\hline IL-6 & U12234 & 10 & 59 & 50 & CCCACCAGGAACGAAAGAGA & 77 & 58 & 50 & CTTGTGGAGAGGGAGTTCATAGC & 68 \\
\hline IL-10 & U33843 & 245 & 59 & 55 & CAAGCCCTGTCGGAGATGAT & 322 & 59 & 52 & CTTGATGTCTGGGTCGTGGTT & 78 \\
\hline
\end{tabular}

Primers were designed using the Primer Express ${ }^{\circledR}$ Software (version 3.0, Applied Biosystems, Foster City, CA, U.S.A.) and several criteria were applied as follows: amplify a template region of 75-150 base pair (bp); maintain a $\mathrm{T}_{\mathrm{m}}$ between 50 and $65^{\circ} \mathrm{C}$; use an $\mathrm{T}_{\mathrm{a}}$ above the $\mathrm{T}_{\mathrm{m}}$; avoid templates with long $(>4)$ repeats of single bases; maintain a GC content of 50-60\%; avoid repeats of Gs and Cs longer than 3 bases; place Gs and Cs on ends of primers and avoid primer-dimer formation. To evaluate the secondary structure of the product, the DNA mfold server of Dr. Michael Zuker (http://mfold.bioinfo.rpi.edu) was used. $\mathrm{T}_{\mathrm{a}}$, annealing temperature; $\mathrm{T}_{\mathrm{m}}$, melting temperature.

a) Positions of genes are given according to accession number.

b) Theoretical melting temperature calculated by Primer Express ${ }^{\circledR}$ Software.

as illustrated in Fig. 1. Although we could not statistically confirm that gene expression changes, similar patterns were always observed in our experiment. Lipopolysaccharide treatment produced a 150-, 1500- and 8-fold increase in TNF- $\alpha$, IL- 6 and IL-10 mRNA, respectively, at 3 to $6 \mathrm{hr}$. However, EP markedly inhibited the expressions of the proinflammatory cytokines, TNF- $\alpha$ and IL-6, in a dosedependent manner at 3 and $6 \mathrm{hr}$. In addition, the expression of IL-10 mRNA was increased at $24 \mathrm{hr}$ following treatment with $10 \mathrm{mM}$ EP.

Because endotoxin can alter both the rate of transcription and the rate of translation for cytokines [3, 6], we also determined the cytokine concentrations in response to LPS and EP. To evaluate the cytokine changes after LPS infusion, plasma TNF- $\alpha$, IL-6 and IL-10 were measured using sandwich enzyme-linked immunosorbent assays (ELISA). The ELISAs were based on commercially available matched antibody pairs (DuoSet ELISA Development Kit, R\&D Systems, Minneapolis, MN, U.S.A.). Assay concentrations were calculated using the SoftMax ${ }^{\circledR}$ Pro software (ver. 5.3. Molecular Devices Corp., Boston, MA, U.S.A.) from the absorbance difference (A450-A540) measured with a microplate spectrophotometer (VersaMax ${ }^{\mathrm{TM}}$, Molecular Devices Corp., Boston, MA, U.S.A.). The detection limits of each cytokine were $15.6 \mathrm{pg} / \mathrm{m} l$ for TNF- $\alpha, 62.5 \mathrm{pg} / \mathrm{m} l$ for IL- 6 and $31.3 \mathrm{pg} / \mathrm{m} l$ for IL-10, respectively. All tests were performed in duplicate.

While LPS increased the proinflammatory cytokines in the supernatant of canine cultured mononuclear cells, EP markedly inhibited the production of these proinflammatory cytokines in a dose-dependent manner. On the other hand, the IL-10 levels increased in the EP-treated group (Fig. 1), while all of the cytokines in the control group (before LPS stimulation and only EP-treated) were below the detection limit.

Here, we observed that EP inhibited TNF- $\alpha$ and IL-6 mRNA expressions and induced IL-10 mRNA and protein synthesis in canine mononuclear cell cultures when EP treatment was simultaneously performed with LPS stimulation. This study indicates that the experimental pharmacological agent EP can modulate the inflammatory response by downregulating proinflammatory cytokines and upregulating anti-inflammatory cytokines after LPS stimulation in canine PBMC cultures. Though the biochemical basis for the antiinflammatory actions of ethyl pyruvate remains to be elucidated, EP appears to have a role in protecting against lethal sepsis [10], hemorrhagic shock $[8,11]$ and ischemia/reperfusion-induced tissue injury $[2,7]$. These results are based on the observed anti-inflammatory role of EP. The results of this study support the potential application of EP for antiinflammatory treatment in dogs. To the best of our best knowledge, this is the first report on the anti-inflammatory effects of EP in canine PBMC cultures. Because EP is not associated with toxicity, the therapeutically achievable and safe dose of EP treatment should be studied further in vivo.

ACKNOWLEDGMENT. This work was supported by a Korea Research Foundation Grant funded by the Korean Government (MOEHRD, Basic Research Promotion Fund, KRF-2008-521-E00153).

\section{REFERENCES}

1. Das, U. N. 2006. Is pyruvate an endogenous anti-inflammatory molecule? Nutrition 22: 965-972.

2. Fink, M. P. 2002. Reactive oxygen species as mediators of organ dysfunction caused by sepsis, acute respiratory distress syndrome, or hemorrhagic shock: potential benefits of resuscitation with Ringer's ethyl pyruvate solution. Curr. Opin. Clin. Nutr. Metab. Care 5: 167-174.

3. Gewert, K., Svensson, U., Andersson, K., Holst, E. and Sundler, R. 1999. Dexamethasone differentially regulates cytokine transcription and translation in macrophages responding to bacteria or okadaic acid. Cell Signal. 11: 665-670.

4. Livak, K. J. and Schmittgen, T. D. 2001. Analysis of relative gene expression data using real-time quantitative PCR and the 2(-Delta Delta C(T)) Method. Methods 25: 402-408.

5. Mallet, R. T. and Sun, J. 2003. Antioxidant properties of myocardial fuels. Mol. Cell Biochem. 253: 103-111.

6. Raabe, T., Bukrinsky, M. and Currie, R. A. 1998. Relative contribution of transcription and translation to the induction of tumor necrosis factor-alpha by lipopolysaccharide. J. Biol. 

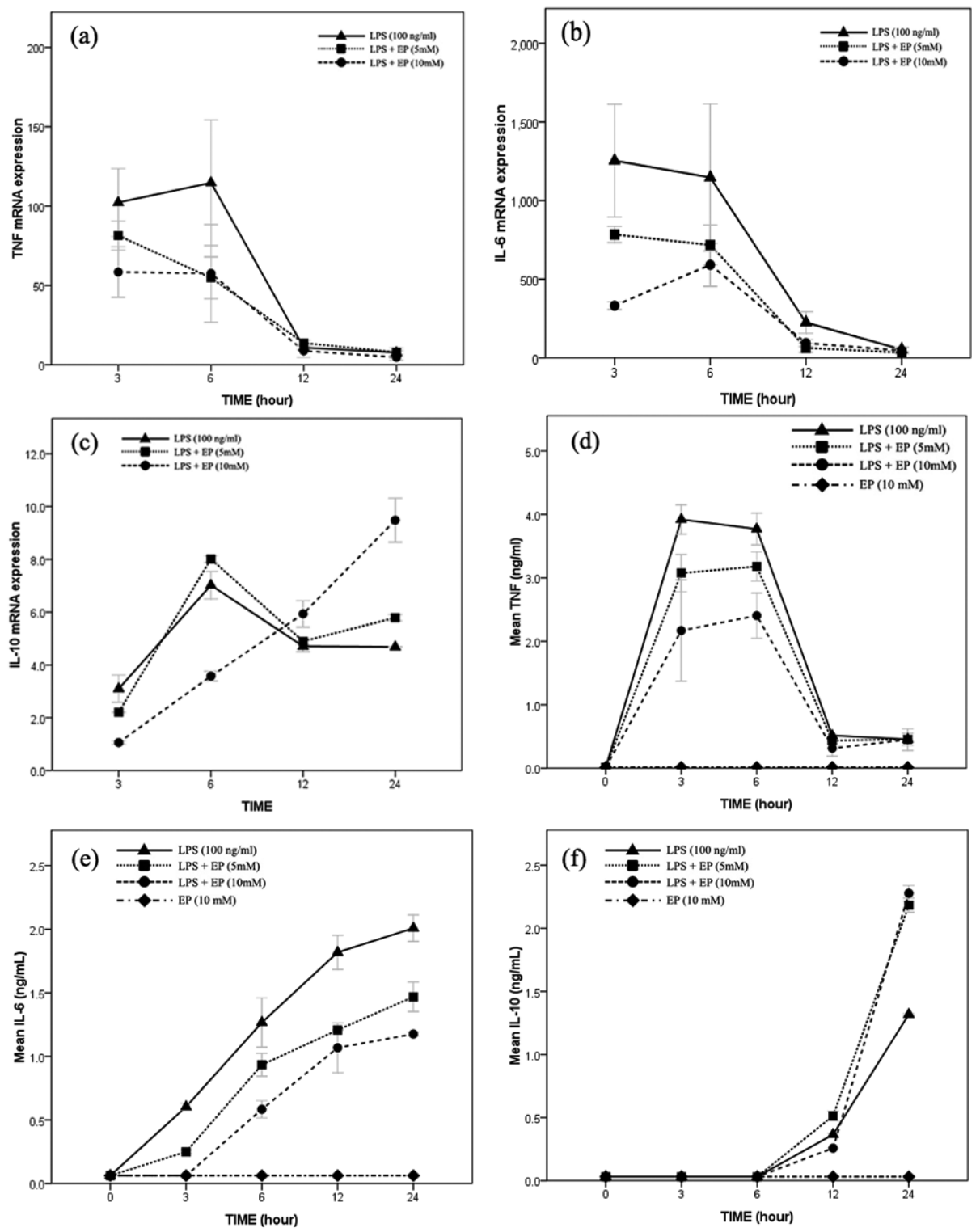

Fig. 1. Relative mRNA expressions and cytokine levels after ethyl pyruvate treatment of LPS-stimulated canine PBMCs. The relative mRNA expressions of TNF- $\alpha$ (a) and IL-6 (b) were decreased by treatment with ethyl pyruvate, while IL-10 mRNA (c) was increased. All mRNA values were normalized to the GAPDH signal in each lane, and the mRNA content of the calibrator (non-stimulated sample) was arbitrarily set at 1.0. ELISA measurements demonstrated that EP also inhibited TNF- $\alpha$ (d) and IL-6 (e) expressions and induced IL-10 (f) production. The data are presented at the mean \pm SEM.

Chem. 273: 974-980.

7. Sims, C. A., Wattanasirichaigoon, S., Menconi, M. J., Ajami, A. M. and Fink, M. P. 2001. Ringer's ethyl pyruvate solution ameliorates ischemia/reperfusion-induced intestinal mucosal injury in rats. Crit. Care Med. 29: 1513-1518.

8. Tawadrous, Z. S., Delude, R. L. and Fink, M. P. 2002. Resuscitation from hemorrhagic shock with Ringer's ethyl pyruvate solution improves survival and ameliorates intestinal mucosal hyperpermeability in rats. Shock 17: 473-477.

9. Ulloa, L. and Messmer, D. 2006. High-mobility group box 1 (HMGB1) protein: friend and foe. Cytokine. Growth Factor
Rev. 17: 189-201.

10. Ulloa, L., Ochani, M., Yang, H., Tanovic, M., Halperin, D., Yang, R., Czura, C. J., Fink, M. P. and Tracey, K. J. 2002. Ethyl pyruvate prevents lethality in mice with established lethal sepsis and systemic inflammation. Proc. Natl. Acad. Sci. U.S.A. 99: 12351-12356.

11. Yang, R., Gallo, D. J., Baust, J. J., Uchiyama, T., Watkins, S. K., Delude, R. L. and Fink, M. P. 2002. Ethyl pyruvate modulates inflammatory gene expression in mice subjected to hemorrhagic shock. Am. J. Physiol. Gastrointest. Liver Physiol. 283: G212-221. 